This item was submitted to Loughborough's Research Repository by the author.

Items in Figshare are protected by copyright, with all rights reserved, unless otherwise indicated.

\title{
Briefing: community resilience to extreme weather
}

PLEASE CITE THE PUBLISHED VERSION

PUBLISHER

(C) Thomas Telford

VERSION

VoR (Version of Record)

LICENCE

CC BY-NC-ND 4.0

REPOSITORY RECORD

Goodier, Chris I., Gavin A. Wood, and Li Shao. 2019. "Briefing: Community Resilience to Extreme Weather". figshare. https://hdl.handle.net/2134/5464. 
This item was submitted to Loughborough's Institutional Repository (https://dspace.lboro.ac.uk/) by the author and is made available under the following Creative Commons Licence conditions.

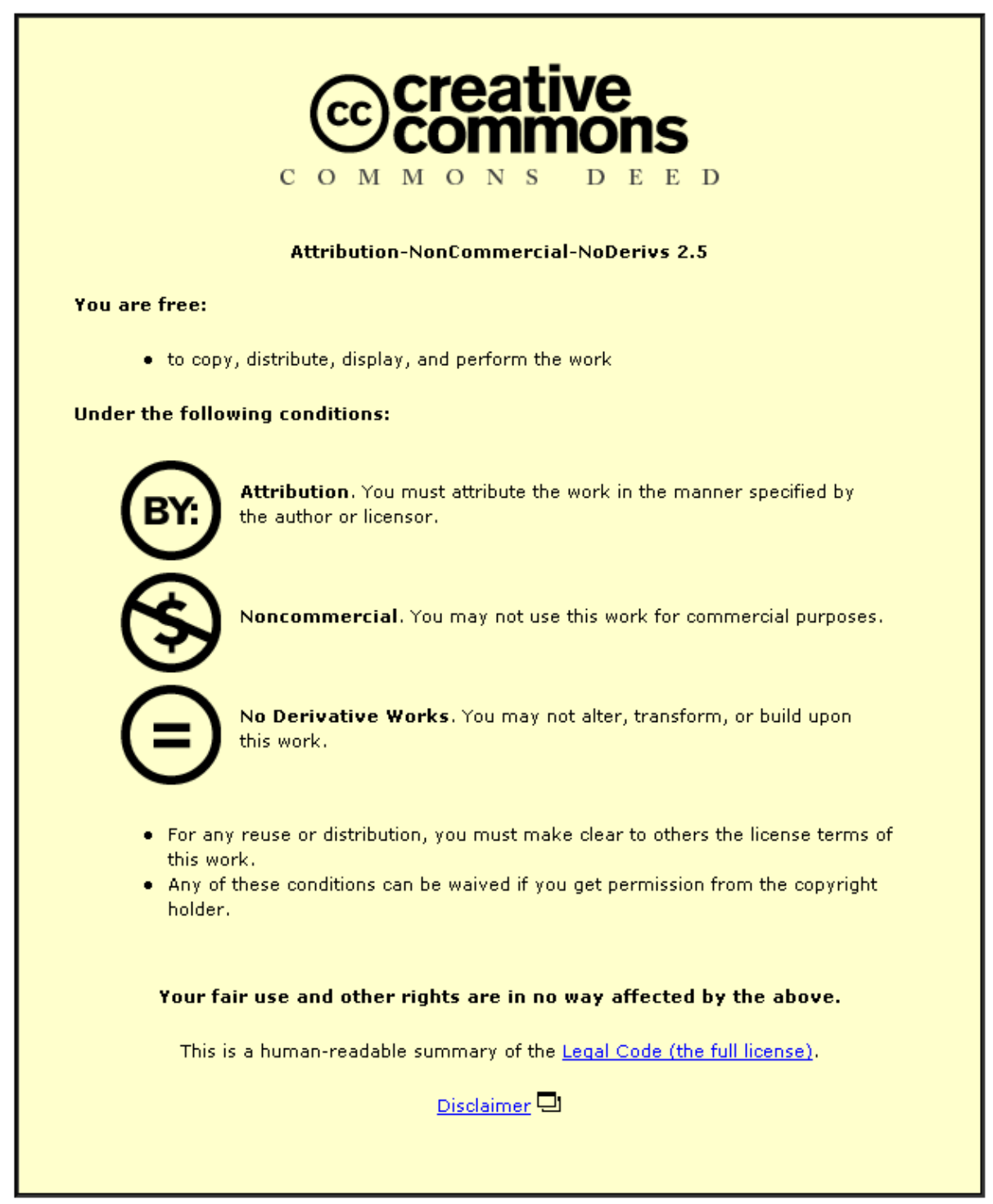

For the full text of this licence, please go to: http://creativecommons.org/licenses/by-nc-nd/2.5/ 


\title{
Briefing: Community resilience to extreme weather
}

\author{
Chris I. Goodier, Loughborough University, Gavin A.Wood, Cranfield University, and Li Shao, De Montfort \\ University, UK
}

The global climate is changing in ways that are likely to have a significant impact on society and the natural and built environments over the coming decades. Extreme weather events, both globally and in the UK, appear to be increasing in frequency and severity, and there is growing concern that the cost of managing them and their impacts will increase. Preparedness and resilience measures can help to mitigate impacts and associated costs to both infrastructure and to people. A new multi-institutional research programme involving 13 universities in the UK called Crew (community resilience to extreme weather) has recently started, which will develop a tool kit to support decision making and will therefore improve the capacity for resilience of local communities to the impacts of future extreme weather. The broad aim is to develop a set of web-based tools for mapping potential future extreme weather events, for assessing their impacts under a range of scenarios, and to evaluate and offer a range of potential coping measures. As part of this the project will identify existing coping measures for dealing with extreme weather events at the levels of the community, buildings and individuals. The work will assess coping measures in terms of their suitability for the climate and buildings in the UK, their effectiveness for risk reduction and technical aspects that may affect their uptake. This will therefore provide the basis for the development of more effective coping measures for the community, including households, small businesses and local policy makers.

\section{INTRODUCTION}

There is now a broad scientific consensus that the global climate is changing in ways that are likely to have a profound impact on human society and the natural and built environments over the coming decades. ${ }^{1,2}$ In the UK, there is evidence that extreme weather events are increasing in frequency and severity, and there is growing concern that the cost of managing them and their impacts on society will rise.

The summer floods of 2007 in the UK provided a stark indication of what may become a regular occurrence, with this one experience costing the insurance industry over $€ 3$ billion $^{3}$ (see Fig. 1). This is in addition to the wider social impacts that continue to affect the local communities involved, which have yet to be fully determined.
Flooding is not the only extreme weather event increasingly occurring in the UK. The incidence of heatwaves ${ }^{4}$ and water resource drought are also projected to increase, particularly in the south of the UK, as climate models predict wetter winters and drier summers. ${ }^{3,4}$ Furthermore, strong storms in Europe have induced, during the last decades, severe human losses and extensive damage to properties.

Preparedness and resilience measures can serve to mitigate impacts and associated costs to both infrastructure and to people. The Crew (community resilience to extreme weather) research programme (funded by the Engineering and Physical Sciences Research Council to the sum of $£ 1.6$ million from February 2008 until February 2011, see www.extremeweather-impacts.net) will develop a tool kit with the aim to support decision making and improve the capacity for the resilience of local communities to the impacts of future extreme weather.

\section{PROJECT SCOPE AND AIM}

The broad aim is to develop a set of web-based tools for mapping potential future extreme weather events, for assessing their impacts under a range of scenarios and to evaluate and offer a range of potential coping measures. The research output should provide a basis for improving the resilience of local communities to extreme weather impacts and for the development of effective coping measures for the community, for example households, small businesses and local policy makers. The tools will allow decision makers to evaluate potential extreme weather event impacts, to develop appropriate intervention strategies and to support the management of impacts on the ground.

The research will be stakeholder-led and involve a unique multi-disciplinary team involving 13 universities in the UK. Engineers, physical and social scientists, modellers and geographers will work closely with building owners, managers and occupiers. This will involve the testing and refining of academic solutions alongside real life situations, with the project outputs being immediately appropriate and relevant to end-users' needs.

The Crew consortium comprises a series of five inter-linked programme packages, delivered as an integrated tool by the fifth. This article focuses on the fourth of these. 


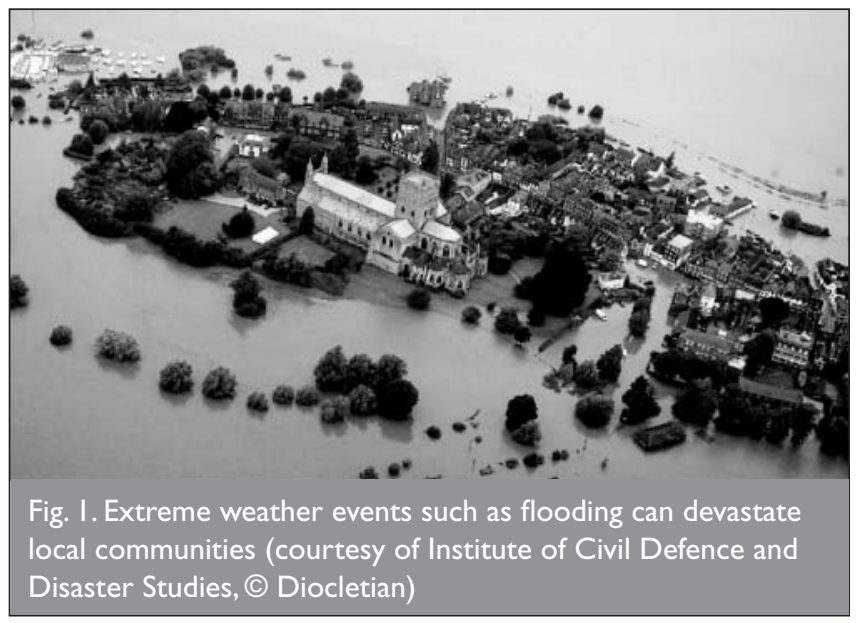

(a) Community hazards: Swerve (severe weather events risk and vulnerability estimator)-the development of a model that estimates extreme weather events for current and future climates at the community level.

(b) Community impacts: Ewesem (extreme weather events socio-economic model)-the development of 'What if?' scenario models for understanding the socio-economic impact of extreme weather events.

(c) Community coping (capacity for resilience): stakeholder-led research to improve understanding of how community groups (policy makers, households and small to mediumsized enterprises (SMEs)) respond to extreme weather events.

(d) Community coping (people and buildings): identification and assessment of existing coping measures for dealing with extreme weather events.

(e) Community tools: WISP (weather impact 'What if?' scenario portal)-the integration of all programme packages into a community-based tool kit for mapping potential future extreme weather events, for assessing their impacts under a variety of future scenarios and to evaluate and offer a range of coping measures. This will be delivered using web-based mapping technologies GIS (geographic information systems).

\section{COMMUNITY COPING MEASURES}

Programme package (iv) will identify existing coping measures for dealing with extreme weather events at the levels of the community, buildings and individuals. For coping with heat for example, potential coping measures could include green spaces and street spraying (community level), solar shading (building level) and fan-evaporation cooling (individual level).

The UK Department of Health has been publishing an annual heatwave plan for England since 2004. ${ }^{6}$ The provision of cool rooms in buildings and in the community is one of a range of key recommendations. While this and other technologies are known to reduce significantly the health risks of heatwaves, ${ }^{6}$ their implementation may leave much to be desired. ${ }^{7}$ The value of solar shading for preventing overheating in buildings should not be overstated but many shading designs in modern buildings, particularly highly glazed buildings, are woefully inadequate $^{8}$ (see Fig. 2). One of the objectives of this part of the project is to overcome these problems by suggesting more

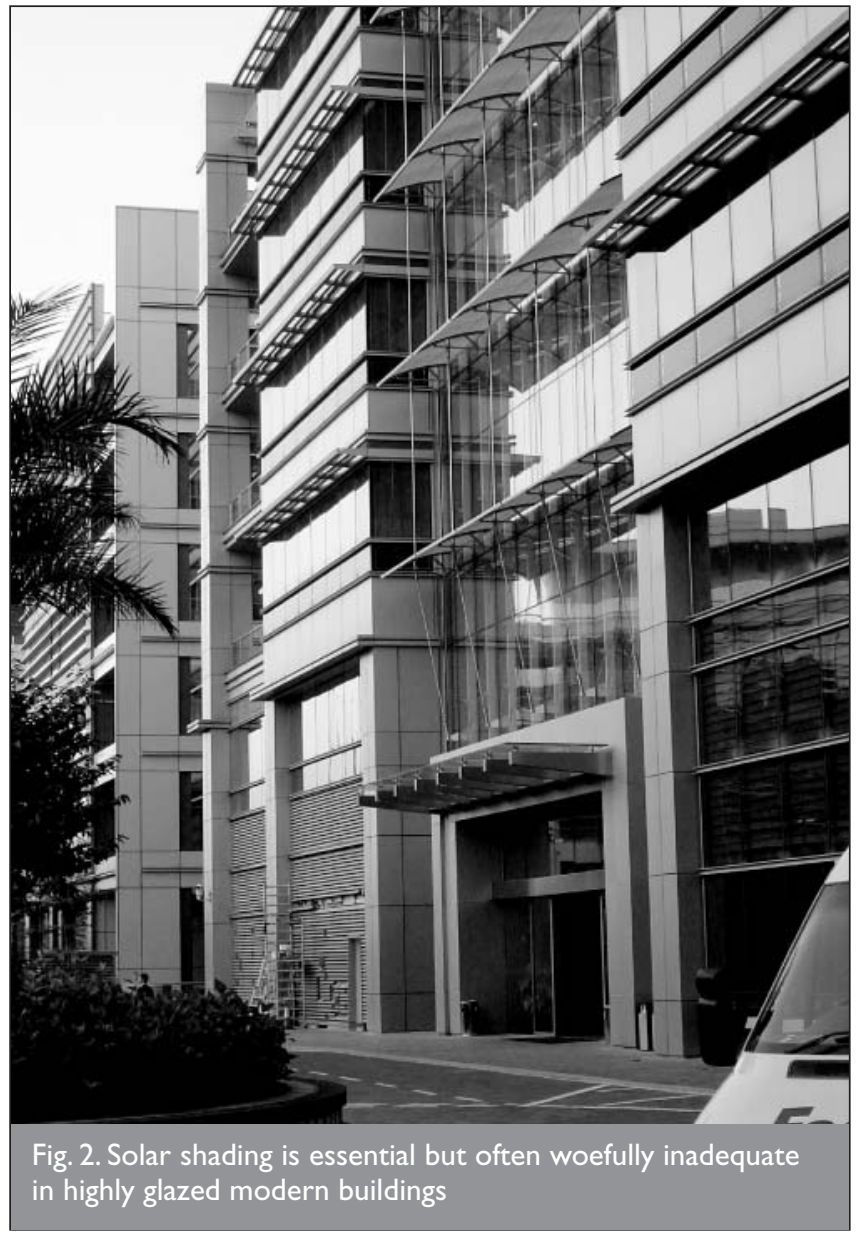

appropriate solutions following an in-depth assessment of various coping technologies.

Technical coping measures based on physics (e.g. heat transfer, fluid mechanics) are the most prevalent ${ }^{9}$ (e.g. radiation shields, flood skirts etc.). People-based coping measures, however, are also effective, for example based on physiology ${ }^{10}$ (e.g. adaptive acclimatisation, slower pace, siesta etc.) and psychology ${ }^{10}$ (e.g. metabolic rate reduction through calming measures and activities).

The work will assess the coping measures in terms of their suitability for the climate and buildings in the UK, their effectiveness for risk reduction and any technical aspects which may affect their uptake. A matrix will be produced of coping measures against an assessment and ranking of their technical performances and potential for wider uptake.

Techniques at the community and building levels are the most prevalent and many are highly effective. ${ }^{11}$ Personal level measures should not, however, be overlooked as they normally do not require significant construction efforts or financial resources and are, in this sense, easier to implement. In addition, physiological and psychological methods have the advantage over many technology-based methods in that they do not produce carbon emissions, which can contribute to the extreme weather in the first place.

The present work will also assess the effectiveness of the coping measures in mitigating the impact of extreme weather. 


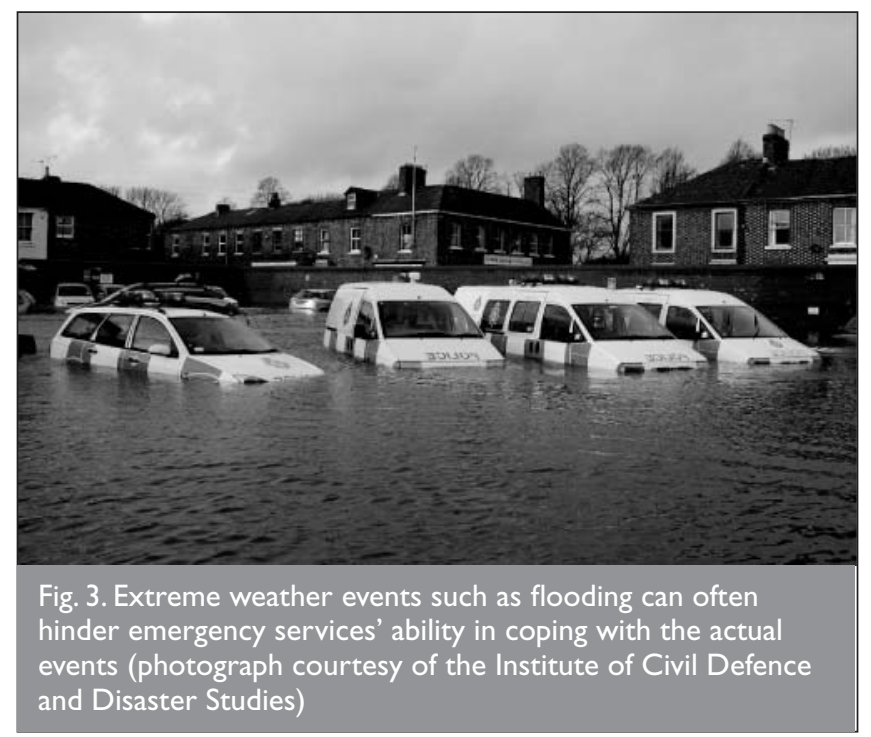

The assessment will involve the review and analysis of existing research literature and historical data. Additional analysis (e.g. lump parameter theoretical deduction and noting uncertainties) will also be carried out. The general suitability of the coping measures for the climate and buildings in the UK will also be considered. In addition to technical performances, aspects of the coping measures affecting their implementation will also be examined. These include, for example, initial, running and maintenance costs, availability of hardware and skills for installation, and the level of intervention required from governments.

\section{OUTPUTS}

The current research will set the foundations for an integrated tool kit, which will aid decision making for coping with extreme weather events. It will also aid the wider uptake of the tool kit within community-scale climate change adaptation strategies and will significantly improve the use of climate change information within such studies. It will provide decision makers, such as local and national government, emergency services, urban planners, SMEs and local communities, with information to help assess the impact of extreme weather events at the local level, all of whom will have been involved in the development of the tool kit (see Fig. 3).

By using web-based mapping technologies such as GIS, there is the added potential to link the programme outputs with a range of public sector spatial systems, which corresponds directly with the aims of the Intra-Governmental group on Geographic Information. ${ }^{11}$

\section{THE PROJECT TEAM}

The project includes senior representatives from the Universities of Birmingham, Cranfield, Coventry, De Montfort, East Anglia, Exeter, Glasgow, Greenwich, Loughborough, Manchester, Newcastle, University College London (UCL), Salford and Wolverhampton, as well as RSK Land and Development Engineering Limited.

\section{REFERENCES}

1. Intergovernmental Panel on Climate Change. Fourth Assessment Report, Climate Change 2007: AR4 Synthesis Report. See http://www.ipcc.ch/ for further details (accessed 02/09/2008).

2. See www.ukcip.org.uk/ for further details (accessed 02/09/2008).

3. Association of British Insurers. Summer Floods 2007: Learning the Lessons, ABI, November 2007, p. 27. See www.abi.org.uk for further details (accessed 02/09/2008).

4. McGregor G. R., Pelling M., Wolf T. and Gosling S. The Social Impacts of Heat Waves. Environment Agency, Bristol, Science Report SC20061/SR6, 2007, p. 47.

5. Chapman L. and Thornes J. E. The use of GIS in climatology and meteorology. Progress in Physical Geography, 2003, 27, No. 3, 313-330.

6. Department of Health. Heatwave Plan for England 2007. Department of Health, May 2007, p. 24.

7. Santamouris M., Pavloua .K, Synnefaa A., Niachoua K. and Коцокотsав D. Recent progress on passive cooling techniques-advanced technological developments to improve survivability levels in low-income households. Energy and Buildings, 2007, 39, No. 7, 859-866.

8. Hernandez Tascon M. Experimental and Computational Evaluation of Thermal Performance and Overheating in Double Skin Facades. PhD thesis, University of Nottingham, UK, 2007.

9. Chartered Institution of Building Services Engineers. Environmental Design. CIBSE, 2006, Guide A.

10. Parsons K. Human Thermal Environments-The Effects of Hot, Moderate and Cold Environments on Human Health, Comfort and Performance, 2nd edn. Taylor and Francis, Abingdon, UK, 2003.

11. See http://www.iggi.gov.uk/ for further details (accessed 02/09/2008).

\section{What do you think?}

To comment on this paper, please email up to 500 words to the editor at journals@ice.org.uk.Your article will be considered for publication in the journal. The original author(s) will also be invited to respond.

Proceedings journals rely entirely on contributions sent in by urban designers, planners, civil engineers and related professionals, academics and students. Papers should be 2000-5000 words long, with adequate illustrations and references. Please visit www.thomastelford. com/journals for author guidelines and further details. 